\title{
The Research-Teaching Nexus and Its Influence on Student Learning
}

\author{
Begoña Gros ${ }^{1}$, Manel Viader ${ }^{2}$, Albert Cornet $^{3}$, Miquel Martínez ${ }^{1}$, Jordi Palés ${ }^{4} \&$ Marta Sancho $^{5}$ \\ ${ }^{1}$ Faculty of Education, Universitat de Barcelona, Barcelona, Spain \\ ${ }^{2}$ Faculty of Psychology, Universitat de Barcelona, Barcelona, Spain \\ ${ }^{3}$ Faculty of Chemistry, Universitat de Barcelona, Barcelona, Spain \\ ${ }^{4}$ Faculty of Medicine, Universitat de Barcelona, Barcelona, Spain \\ ${ }^{5}$ Faculty of Geography and History, Universitat de Barcelona, Barcelona, Spain \\ Correspondence: Begoña Gros, Faculty of Education, Passeig Vall d’Hebron, 171. 08035 Barcelona, Spain
}

\author{
Received: January 21, 2020 \\ Accepted: March 3, 2020 \\ Online Published: March 12, 2020 \\ doi:10.5430/ijhe.v9n3p109 \\ URL: https://doi.org/10.5430/ijhe.v9n3p109
}

\begin{abstract}
The relationship between teaching and research in universities has been widely studied in the higher education literature, but no clear relationship between the two has been identified. Nevertheless, in recent years, research has been linked to a form of teaching that is more focused on the development of competences and learning capacity through enquiry and the generation of new knowledge. In this context, it is important for teachers and students to work together on the design of shared spaces for research and learning. This work examines the case of the University of Barcelona to analyse whether there is enough connection between research and teaching to allow students to experience this link and to successfully develop research competences. Teaching plans of the academic year 2018-19 were screened to identify research-related competences, the modules they appear in, and the descriptions of the evaluation systems. This information was compared to the students' perceptions of the actual training they had received on these research competences. Results showed that teaching plans establish numerous competences related to research and generating new knowledge. However, students consider that this knowledge is not developed until the final year project.
\end{abstract}

Keywords: research-teaching, teaching-learning-research, student participation in research, research competences

\section{Introduction}

The study of the relationship between the teaching-learning process and research is a much-debated subject in the higher education literature. In recent years, there has been a significant development in how this topic is considered, shifting away from focusing mainly on the activity of academic staff and how they manage their time (as seen in some of the examples studied in the seminal article by Hattie and Marsh, 1996), towards a much broader approach that encompasses the central role of students, a deeper exploration of the possible synergies between teaching-learning and research, and aspects related to institutional culture and university policy. Elken and Wollscheid (2016) provide an excellent review and analysis of this topic.

At the same time, many research-intensive universities (sometimes organised into networks such as the Russell Group or LERU) are calling for the powerful results of research to be used effectively and transferred to excellent and innovative education (LERU, 2017). Essentially, this means going beyond the traditional notion of good research guaranteeing good teaching (as the teaching content could be cutting-edge scientific knowledge), and instead exploring more thoroughly a subject that by its very nature is highly complex, and generating suitable institutional policies based on this analysis.

The University of Barcelona is a member of the League of European Research Universities (LERU) and, since the reform instituted as part of Spain's integration into the European Higher Education Area, the study programmes for various courses at this university include different research competences. This work examines the case of the University of Barcelona in order to analyse whether there is enough connection between research and teaching to allow students to experience this link and successfully develop research competences. 


\section{Literature Review}

\subsection{The Relationship between Research and the Teaching-Learning Process}

When tackling the issue of the relationship between research and the teaching-learning process in higher education, it is important, first of all, to consider some conceptual and definition problems that complicate any analysis of a topic that is already complex by nature.

One fact highlighted by the extensive literature on this subject is the need to adopt a broad and comprehensive approach that encompasses not only the Teaching-Research Nexus (TRN), as occurs in many cases, but which also considers the triad of the Teaching-Learning-Research Nexus (TLRN) or the Research-Education Nexus (REN). A wider vision is required, which includes not only the specific activity of academic staff and students, but which also takes into account aspects of organisation, leadership and institutional culture. Along these lines, Elken and Wollscheid (2016) explicitly distinguish the relationship between research and teaching, in which the 'unit of analysis' is the teacher, from the relationship between research and learning, in which the unit of analysis is the student. Naturally, recognising the link between these two aspects raises the need for a more global vision of these questions.

There are also difficulties with the definition of research itself, which have been discussed from different points of view, especially regarding its nature and methods across diverse disciplines. It is evident that this has an impact on defining the role of research in the teaching-learning process and the forms this relationship can take. We should mention here the classic distinction between 'pure' or 'basic' research, normally linked to specific and well-defined disciplinary areas, and research that is 'applied' to tackling concrete 'real-world' problems and challenges, usually of a more multidisciplinary nature. Despite its shortcomings and overly simplistic character, this distinction can be useful when discussing this matter, and it has been developed to greater and lesser extents by various authors, for example, as 'type 1 research' and 'type 2 research' (Gibbons et al., 1994). In some cases, the exploration of this distinction has led to interesting developments in specific areas. To cite just a couple of examples, the work of Huff and Huff (2011) and Saunders (2011) in the area of management, based on an analysis of levels of applicability of the knowledge generated by research, are both important. In many other cases the distinction is relevant, in spite of often being implicit, and particularly so in fields with a strong scientific and professional dimension such as, for example, medical studies (Laidlaw et al., 2012; King et al., 2016). This raises the very important issue of the role of research competences in the professional arena.

There are other approaches to research that may contribute interesting descriptive and interpretative elements. Some are based on the perceptions and attitudes of researchers themselves as a way of distinguishing between more or less implicit notions of research (for example, Brew, 2001) or the relationship between conceptions of research and other elements, such as scientific productivity (Brew et al., 2015); others, as already mentioned, prefer to emphasise the differences among disciplines (for example, Becher and Trowler, 2001; Trowler and Wareham, 2008; Healey and Healey, 2018).

In addition to important terminological and conceptual issues, a critical review of the literature on these themes reveals other weaknesses: the lack of an exhaustive analysis of the different levels, both disciplinary and organisational (departmental, university, etc.); the existence of starting points and regulations that influence the focus of research such as, for example, the presupposition that the teaching-learning-research relationship exists necessarily or by definition; a certain lack of theorisation, with a large number of mainly or totally empirical works; the tendency to use rather vague terminology to describe the connection being studied; and the absence of strong causal models. A useful review of some of these points can be found in Trowler and Wareham (2008).

It is also important to point out some tendencies and conceptions that can be found in the literature on this subject, and which have significant implications:

- In many studies there seems to be an implicit (or sometimes even explicit) presupposition that the relationship between education and research is asymmetrical, and that research should inform and guide teaching and learning, while the impact in the opposite direction appears less clear and, in any case, generally receives less attention. However, there are important exceptions to this approach, such as the work of Harland (2016) and Charles (2018), which develop the concept of teaching-led research.

Although the teaching-learning-research nexus is often considered to be especially relevant or powerful in postgraduate-level studies, there is a growing trend towards focusing on the need to strengthen this type of link in degree studies as well (Healey and Jenkins, 2009, 2018; Hensley, 2015). In general, the concept of research-led education, which is very important in research-intensive universities, is proposed for all educational levels, although 
it may take different forms in each one (LERU, 2017). In some cases, this even refers to actions to be taken specifically with first-year students (Levy and Petrulis, 2012). The Undergraduate Research Opportunities Program (UROP) initiative, which is discussed briefly below, is a clear example of the interest in engaging undergraduate students in research.

- The different notions of the teaching-learning-research link also play an important role in the debate surrounding the concept of educational excellence based on research (LERU, 2017) and the criticism that has been levelled at this idea (Charles, 2018).

\subsection{Basic Connections in the Research-Education Relationship}

As mentioned earlier, various aspects can be identified in the research-education relationship. First of all, when talking about the teaching-research connection, it is important to bear in mind that this refers above all to the different activities carried out by academic staff, the connection among them, the way they are focused and the distribution of the time dedicated to these tasks. These factors have an impact on student learning through aspects such as the type of teacher, their training, their level of scientific qualification and the time they dedicate to their teaching activity. A contrast can be observed between the importance academic staff and institutions theoretically place on this relationship and the often inconclusive or even apparently contradictory results obtained in empirical studies. This viewpoint is also found at the heart of discussions surrounding academic staff's working hours and how they are divided among various activities; a perspective that appears logical, albeit overly simplistic, as it often seems to be based on a radical separation of teaching and research activity, without considering or studying the possible synergies between them. Drawing on a debate encountered in many fields, and using deliberately provocative language, McKenzie et al. (2018) maintain that university and government policies have played a decisive part in weakening or even destroying the relationship between teaching and research in the activity of academic staff.

Hattie and Marsh's (1996) seminal contribution on this subject suggests different models of relationship between teaching and research activity and specifically analyses the link between scientific productivity and teaching effectiveness. Their meta-analysis, based on multiple previous studies, found a practically null correlation between these two elements. Subsequent studies continue to present ambiguous or contradictory results. A recent review of the literature can be found in Elken and Wollscheid (2016). The direction and strength of the teaching-research relationship seem to depend on factors such as the particular discipline, the type of student, the type of teacher and the orientation of the study programme.

In turn, the research-learning connection is understood as the analysis of the relationship between the contact students have with research (including research activities, and not only the availability of up-to-date information) and the quality of their education. In general, there is remarkable agreement in the literature in recognising the benefits of learning based in some way on research, although this positive influence must be contextualised and may be affected by various factors and, critically, by the type of activities proposed. These activities, in turn, depend to a great extent on the conception of the relationship between the teaching-learning process and research and the way of focusing the curriculum.

The literature reveals different proposals for identifying and describing the various types of relationship that may develop between the teaching-learning process and research. In addition to their conceptual value, these proposals can be useful for diagnosing the specific situation in different universities, as well as in different disciplinary areas. Some of these contributions were made by Hodson (1992), Healey (2005), Levy and Petrulis (2012) and Dekker and Wolf (2016). From the alternative perspective of learning support services, Hensley (2015) approaches this topic from an interesting angle, in terms of the relationship between students and knowledge, in a continuum that ranges from the student as a consumer to the student as a knowledge producer.

Probably the best known and most influential of these contributions is that initially put forward by Healey (2005) and later by Healey and Jenkins (2009). These authors propose two fundamental axes: an emphasis on research content in a disciplinary area versus an emphasis on research processes and problems; and, the degree of student participation in research tasks.

There is an observable trend in one part of the literature to talk about education not strictly based on or oriented towards research, but about inquiry-based learning (IBL), which is generally understood as an active learning strategy rooted in identifying and resolving questions, problems or scenarios. Using this approach, it is possible to incorporate some (not necessarily all) elements of professional research into the teaching-learning process, allowing for interdisciplinary diversity while preserving some central features such as identifying and solving problems or 
establishing relationships among variables (Keselman, 2003; Levy and Petrulis, 2012). Naturally, the degree of connection and approximation of the concept of IBL to the previously mentioned types of education may vary, depending on the specific activities included, and in some cases, IBL will almost certainly be indistinguishable from other, already developed concepts.

At many universities there are good practices that involve a certain amount of student participation in research activities. Visser-Wijnveen et al. (2010), drawing from the typologies proposed by Healey (2005), identify specific activities that can be linked to general profiles: teaching or making known research results (research-led), showing what it means to be a researcher (research-guided), helping to conduct research and providing research experiences (research-based).

Some studies on academics' perception of this issue allow us to identify a series of questions that help to obtain a clearer picture of real situations. For example, Brew and Mantai (2017) distinguish the following aspects: span (research for all students or specialised processes only for specific groups?); level of guidance (guided research vs independent research); process (student involvement in the entire research process or only specific parts, such as data collection?); focus (on developing skills and/or on students' attitudes?); quality (research with low expectations of quality or more powerful, with publication potential?; identity (students identified as researchers within their own context or considered as members of the research community and future researchers?).

Different proposals have been presented for systematising student engagement in research activities. Brew (2006) advances the concept of scholarly knowledge-building communities. Along the same lines, Healey et al. (2014) propose a conceptual and practical framework called Students as Partners, taking a term that was already in use and later developed further (Cook-Sather et al., 2018). The basic idea hinges on seeking formulas for establishing shared research and learning spaces in which academic staff and students form a partnership. This concept is currently a hot topic in higher education and has led to the development of a whole line of work and even boasts specialised journals, such as the International Journal for Students as Partners.

An important initiative in this area are Undergraduate Research Opportunities Programs (UROP), commonly found in English-speaking countries, although similar initiatives exist in other contexts. UROP are specifically designed to encourage undergraduate engagement in research alongside academic staff, through various modalities and initiatives. At some institutions these programmes have existed for many years, as is the case of MIT (programme launched in 1969) and Imperial College London (since 1980), among many others.

One common element that allows a solid foundation to be laid for the relationship between teaching-learning and research is curricular design based on or inspired by research. The idea of curriculum design is not only grounded in the question of what content forms part of a certain study programme, instead it is a much more dynamic concept that encompasses all the significant activities and connections that can improve student learning, some of which can be established in the study programme and others through the practices derived from it. There still seems to be a need for a more systematic study of the specific elements to be considered when integrating research into higher education curricula, although there have been important contributions such as, for example, that produced by Griffioen, Groen and Nak (2019) after an exhaustive analysis of previous studies, in which they identify 10 basic curricular aspects to take into account. Fung (2017) and Carnell and Fung (2017) present different experiences developed around the central concept of the 'connected curriculum', including those carried out at University College London. This case is particularly interesting because of its broad scope and the fact that it is linked to the university's strategic planning (UCL Education Strategy 2016-21 and UCL 2034). The idea of a connected curriculum relates to questions such as students' connection with the institution's researchers and research; the construction of a line of continuity or argument based on the research activity in each programme; the connections formed between different subjects and disciplines and subjects outside the academic world; the link between academic and professional learning; students' capacity to produce results that can be presented to an audience, and students' connections with each other and with alumni.

As the literature analysis shows, some common problems in the study of these issues are closely linked to two elements: the first, as already seen, relates to the need to precisely define the terms to be used and a suitable theoretical framework; the second concerns the need for empirical references that provide meaningful information. This second aspect includes both identifying pertinent variables and indicators and determining the relevant agents and sources of information that should be used. In this regard, and along the lines of other empirical studies, we believe that the opinion of students is particularly important, both as key figures in the teaching-learning process and as people who can assess the implementation of the objectives set in the study plans from their own specific point of view. 
In light of the broad trends detected in higher education, it could be especially productive to emphasise an analysis linked to the concept of competence, which has become key to the configuration of higher studies and its actual realisation in terms of teaching, learning and evaluation activities. If, as usually occurs, study programmes define competences explicitly or implicitly related to skills and attitudes found in research, analysing the associated activities may provide a closer understanding of the real situation and could help to identify the role of research in the development of the teaching-learning process. In this study, we have approached this subject through an analysis of different courses offered at the University of Barcelona.

\section{Method}

To analyse the teaching-research nexus at the University of Barcelona (UB), we selected the most 'traditional' degree courses that cover the four main knowledge areas at the UB: Humanities and Social Sciences, Economic and Legal Sciences, Experimental Sciences and Health Sciences. Specifically, the following degrees were chosen: Law, Electronic Engineering, Physics, History and Medicine.

Two complementary lines of analysis were pursued. First of all, we identified research-related competences in the teaching plans for the 2018-19 academic year and the modules they appear in, and gathered descriptions of the evaluation systems used by teachers. Then, this information was contrasted with the students' perceptions of the training they had received on these research competences.

To obtain the students' perceptions, we conducted four focus groups selected from a convenience sample distributed in the following ways:

1. A group studying law, formed of seven undergraduate students.

2. A group studying physics and engineering, formed of five students (two engineering undergraduates, two physics graduates currently studying for their doctorates and one student taking physics and mathematics).

3. A group studying history formed of four final-year students.

4. A group studying medicine, formed of four second-year residents. All of them graduated in the first year of the Bologna Process (2009-2015)

\section{Results}

\subsection{Law Studies}

In the law studies, three specific competences related to research were identified. Those most commonly found are linked to managing knowledge sources. In fact, the effective management of knowledge sources competence appears in 15 courses in the law programme. However, this broad presence contrasts with the students' opinion. In general, the students felt they had not received training related to research and mentioned that they had difficulty searching for information and, particularly, accessing resources. The example most often provided by students was the lack of access to court rulings. They stated that they seldom received lectures on rulings and jurisprudence.

The students also considered that the teaching methods used were purely transmissive and disconnected from current examples. They believed that teachers should transmit and highlight the research they are doing in order to motivate and incentivise their students' knowledge. They should also provide documents and articles and demonstrate how they relate to research.

The academic staff do not usually talk about their research, or what they are studying; 'I think that when explaining a topic there are teachers who give us examples that arouse our curiosity and encourage us to search for research articles they have written or read and which are very useful for understanding the topic they are teaching us about' (Law 2). The university 'should place a greater focus on research, to know what those teachers who really apply a regime of continuous evaluation are thinking — and I have encountered few of these, honestly-, as those who do so promote research know-how because they make you come to class, they force you to participate, to search for information and not only take an exam and later forget everything' (Law 1).

A positive aspect pointed out by students was that in some modules they could improve their grades by conducting 'a little research' to study a particular point in greater depth. 'I did some research to gain a better grade in one subject and I found it very interesting. The exam is more or less easy as long as you attend your lectures, take notes and understand what you learn. In the coursework you have to investigate, so it is very helpful to read different opinions and articles and then form your own ideas and put them in writing. I think it is very useful that we are set this type of task and, above all, it helps a great deal if you are given the right tools' (Law 1).

Another positive aspect is the first course they take on working techniques, although they felt that it had little bearing 
on the rest of their subjects and what they had learnt was not applied later in the course.

\subsection{Engineering and Physics}

In the engineering studies, 13 general degree competences connected with research were identified. Those most commonly found in the different modules are linked to problem-solving using initiative, creativity and decision-making, teamworking and the ability to work in multidisciplinary groups.

In the physics degree course, we found eight general competences related to research. Of particular note is the capacity for analysis, synthesis and adaptation to new situations, which is present in 12 modules.

The final year project (FYP) is the task that includes the evaluation of the competences most closely linked to research. The FYP is conceived as an introduction to research work in which students have to choose a topic from a list provided by their tutors. Given that the FYP is designed as a piece of work involving research methodology, it should be presented in the standard format of the most important scientific journals in the field of physics. The finished work is presented publicly and also corresponds to the usual format found at the conferences where academic staff disseminate their research projects.

In engineering, just as in the physics degree, students must select the topic for their FYP from a list. However, one of the differences is that work related to tutor-led activities in company is also accepted. This aspect was introduced to respond to the high demand for engineers in local firms.

In the focus group made up of physics and engineering students, the participants felt that during their degree courses they had obtained competences in teamworking, independent learning and analysing scientific articles. All agreed that the FYP is the first moment at which they truly learnt how to conduct research. They also believed that from the first year, the teaching staff should transmit and highlight the research being conducted, introduce students to the faculty's research groups and the subjects they are working on, etc.

The physics students believed that they seriously lacked training on how to search for information, access resources, articles, etc. They stated that 'teachers feel that they are wasting time if they have to dedicate class hours to matters relating to searching for information'.

The engineering students had a more positive view, as they have access to some elective modules that teach them to search for information, but the physics students were more critical. On this matter, one student stated that 'on this degree course we don't work on the communication competence, we are not shown how to give presentations or communicate, or even taught scientific writing to present papers at conferences or as articles. Until the FYP, we hadn't ever read a scientific article' (Physics 1).

We should mention that most of the students expressed a great deal of ignorance of the academic staff's research and knowledge transfer activities. They proposed that this type of information be included in reception sessions and that the research activities and projects academic staff in each subject are involved in be presented in a classroom session.

\subsection{History}

In the degree in history, we found eight general competences related to research. The activities and evaluation methods are highly diverse but, unlike the other courses studied, in many of the modules students are offered questionnaires and self-evaluation activities. There are exams and written tests, but they only account for approximately $40 \%$ of the total evaluation. The rest of this figure is taken from the sum of various types of activity: essays on material, debates on readings, presentation of students' work, oral commentaries on text and audiovisual documents, etc.

The history students felt that there is a huge gap between the content of the teaching plans and what they really did during their degree courses. Although they recognised that certain practices introduce them to research experience, their sensation was that it was insufficient. All the history students who participated highlighted that there was a lack of work using direct sources. In their opinion, very few of the modules they took provided them with information regarding the use of primary sources, albeit often limited to glossaries and lists, and they did not do any meaningful work using these sources. In some cases, they stated that at no point during their degrees did any teacher ask them to search specialised archives, and that the research tools they were shown are insufficient for tackling a real project.

The students were particularly critical of the FYP, as faculty rules expressly forbid the use of primary sources, although in some cases their tutors, in agreement with students who expressed their consent, ignored this instruction. They did not understand why a final year project in which, supposedly, they must demonstrate what they have learnt, has to be limited to a state of affairs drawn from a specialised bibliography. This criticism of the FYP stems from the fact that it really is just another subject on the degree course and they do not necessarily learn to conduct research, 
even though they also felt that it was the first type of work truly linked to research. From the FYP onwards the students have more direct contact with their tutor and this encourages them to consider the possibility of conducting research. During the degree, sometimes 'the academic staff transmit information about their research and include it in the bibliography, but they do not explain how they carried it out. It would be great if they gave us more details about how they do this'.

The students also admitted having certain difficulties with skills such as bibliographical research, awareness of quality journals and searching online for reliable resources, which shows that they are not acquiring some of the essential cross-disciplinary and specific competences they should during their degrees.

They do believe that they had developed the capacity to synthesise ideas, but bemoaned a lack of training on the use of ICT applied to history research, something they consider very serious given that we are living in a digital world. They also recognised that, despite being digital natives, their knowledge of research tools (databases, GIS, spreadsheets...) was limited. Their perceptions could be summed up in this statement: 'History content can be learnt without going to university; we come here not to learn about history, but to become historians'.

They suggested introducing practical exercises more closely linked to research and working with sources, both in their documentation centre reading activity (in archives, libraries...) and in objective-focused selection criteria, how to use ICT for this purpose and even in the initial design of a study (defining objectives and methodologies, state of affairs...). Moreover, they considered that these practices should be incorporated into all areas or modules for each period (prehistory, classical world, medieval era, modern and contemporary ages). These proposals are aimed at a greater use of research practices in their studies. They also asked that in each module they be pointed towards sources that can be used to study a particular point in greater depth, in the same way as they are given a specific bibliography.

\subsection{Medicine}

In the degree in medicine, 14 subject-specific competences were identified. Those most commonly found in the teaching plans are linked to the capacity for analysis and synthesis, problem solving and teamwork. The most important element of the evaluation are multiple choice tests, which generally account for $60 \%$ of the final grade, complemented by clinical practice and seminars.

The degree uses the evidence-based medicine paradigm in its teaching and therefore in one way or another emphasises that the content being taught is based on research. This is very typical in the basic modules, in which students are given examples of the research that has generated the knowledge being taught.

The medical students in this study stated that during their studies they are expected to acquire competences in specialised bibliographical searches, finding information and accessing databases and using specific search engines, but they had difficulty applying biostatistical knowledge as their training is highly theoretical: 'It is not a case of providing formulas, but of explaining which statistical tool should be used and when. In fact, the statistical parameters are calculated by statistical programs' (Medicine 1). All the participants agreed that the biostatistics module should be restructured to make it more useful.

During their degree courses the students read scientific articles, but due to a lack of knowledge they very often felt incapable of developing critical analyses. The FYP provided a practical opportunity to apply the theoretical knowledge they had acquired, but they stressed that it should not be their only chance to do so. They also highlighted the training on research competences provided by their FYP tutors.

The students proposed carrying out exercises on critical analysis and the methodology of scientific articles in each module of the degree, interpreting studies in small groups in various modules, which could then be included in the evaluations, creating elementary or basic study designs and conducting more exercises on applying theoretical knowledge.

\section{Discussion}

Although the concept of research in the different studies analysed is different, there are many common situations. The teaching plans establish numerous competences related to research and generating new knowledge. Nevertheless, these plans do not usually explain how these competences are to be obtained and evaluated.

During the first or second semester it is very common to introduce modules related to searching for sources of scientific information and resources, but its subsequent application throughout the course is poor and this knowledge is not generally utilised until the FYP.

There was clear agreement among all the participants that the FYP is the only point when research work is 
specifically set as a task. Despite the statements regarding the importance of interaction among research, teaching and learning, our analysis identified a series of shortcomings that highlight the need to develop specific actions to achieve this objective. Such actions should be of an institutional nature and bring about change in the academic staff's teaching culture. Even though these issues were identified in the context of a specific university, the characteristics of the Spanish and Catalan university systems, which have highly uniform regulations, suggest that many of the identified issues are generalizable to at least these systems. From the analysis of the results of this study, some actions and recommendations are derived.

Specific actions

a) As regards teaching plans

1) Review teaching plans and real teaching activity in each course to guarantee an adequate presence of academic time and attention to students that fosters a critical spirit and regular exchange of opinions based on an analysis of research practices and results.

2) For each subject, set aside specific time and activities for this purpose and ensure that these are well publicised and shared among the academic staff in each knowledge area.

3) Establish indicators linked to student participation in these activities as a learning evaluation criterion.

4) Incorporate activities that systematically inform students about the usual sources of research and innovation in their fields of study, teach them how to search for and select information, and how to consult and obtain reports, articles, court rulings and other specialised resources.

b) As regards fostering interest in and raising awareness of research

1) From the second semester of degree courses, promote master classes in large-group format delivered by academics renowned for their research and with demonstrated ability to communicate knowledge, in which they present some of the most exciting and relevant research for each degree course.

2) Accompany these sessions with forums for debate and discussion in small groups in which trainee research staff can also participate.

3) Engage students, especially from the fifth semester, in research activities through IBL contexts (Brew, 2003, 2006; cited by Gonzalez, 2010).

4) Encourage academic staff to adopt a reflective, motivating attitude and be open to debate in their usual teaching activity with the aim of fostering a critical understanding of knowledge.

c) As regards mastering instrumental competences

1) Offer students spaces for learning to communicate well orally and in writing using contributions from academic writing.

2) Promote the creation of reports and infographics using digital tools.

3) Teach students how to choose and use the right statistical tools to process data and to read and understand scientific articles and reports without difficulty.

4) Inform students about the research groups related to their studies and about the bursaries and grants available, as well as how to apply for them in order to join research teams and projects.

d) As regards final year projects

1) Consolidate the approaches proposed by the FYP as an introduction to research and conduct an in-depth review of the approaches that view the FYP as just another module.

2) Propose, if not already being done, that part of the FYP should consist of writing an article in the standard format and style of a research article in the disciplines closest to the degree and the topic of the final year project.

3) In the final evaluation of the FYP, pay particular attention to the review of the state of the art of the topic of study and the summary of articles and reports on the most relevant research.

4) In the final evaluation of the FYP, grade the students' oral and written argumentative skill and communication competence.

Finally, some more general considerations or recommendations could also be derived from the work as a whole, including the following four: 
- Implement a research-based teaching-learning process (in Healey's terminology), that is, one linked to research processes and not only content, and with the active participation of students; demand a more ambitious strategic approach from universities accompanied by profound changes at various levels (organisational, financial, teacher training, etc.) and the corresponding alignment of governmental policies. It is important to foster, protect and disseminate existing good practices but, at the same time, transcend them through a more systematic approach in different directions.

- In particular, the academic staff's research capacity is important, but it is not enough to guarantee the existence of a research ecosystem capable of having a powerful impact on student learning if it is not accompanied by elements that facilitate student engagement in research processes, according to the characteristics of each educational level (degree, master, doctorate).

- Linked to the previous point, it is necessary to carefully assess the role of research at all educational levels, connecting them to the different typologies of teaching-research nexus. In this context, it could be important to explicitly include continuing education. The presence of important research elements (not simply the presentation of content) could be one of the distinctive features of continuing education provided by universities, compared with other proposals.

- It is important to avoid exclusively linking the acquisition of research skills and attitudes with the perspective of an academic or research career; we should strengthen the bond with the professionalisation process, with an impact on curriculum design and relevant learning situations. Fostering a research attitude is fundamental in the education of critical and proactive professionals.

\section{5.- Limitations and future directions}

The current study analysed an institution, the University of Barcelona, that is part of the LERU and which proactively works to adapt to the trends of the European Higher Education Area. Although there is reason to believe that many of the results and conclusions drawn from this study can be generalized to similar universities, it would be interesting to explore these issues in other types of university systems as well. We believe that the approach used here, which analysed research-related competencies and how they are trained within different study programmes, could be useful for future work. Although the procedure proposed in this study needs to be tested on different university degrees, we believe it may be useful for various types of higher education institutions, and could serve as a basis to guide political decisions at different levels of each organization.

This study followed a qualitative approach, with selected groups of university degrees and students. This allowed us to identify meaningful opinions, perceptions and situations. The current study, and in particular the content of the discussions by the focus groups from different degree courses, may provide a basis for expanding the research focus in future studies. For example, questionnaires could be developed based on the information obtained in the small group discussions that may allow for a more powerful analysis based on quantitative data. While sampling students from a broader range of university degrees could bring new elements into the discussion, we believe the information collected in this study already reflects most of the relevant topics. It is also important to consider the need to relate the information derived from in this and future work with the content and results of internal and external processes of evaluation and certification of university degrees. In this regard, the analysis of the mechanisms that should allow to improve the methodological training and promote a more active involvement of the students in research processes should be strengthened.

\section{Acknowledgements}

This contribution is the result of the project REDICE-18- 2120 supported by ICE-IDP at the University of Barcelona.

\section{References}

Becher, T. \& Trowler, P. (2001). Academic tribes and territories: intellectual enquiry and the culture of the disciplines. London: Routledge.

Brew, A. (2001). The nature of research: inquiry in academic contexts. London: Routledge/Falmer.

Brew, A. (2006). Research and teaching: Beyond the divide. Palgrave McMillan.

Brew, A. \& Mantai, L. (2017). Academics' perceptions of the challenges and barriers to implementing research-based experiences for undergraduates. Teaching in Higher Education, 22(5), 551-568. https://doi.org/10.1080/13562517.2016.1273216

Brew, A., Boud, D., Namgung, S., Lucas, L. \& Crawford, K. (2015). Research productivity and academics' 
conceptions of research. Higher Education, 1-17. https://doi.org/10.1007/s10734-015-9930-6

Carnell, B. \& Fung, D. (2017). Developing the higher education curriculum. London: UCL Press.

Charles, M. (2018). Teaching in spite of excellence: Recovering a practice of teaching-led research. Studies in Philosophy and Education, 37, 15-29. https://doi.org/10.1007/s11217-017-9568-

Cook-Sather, A., Matthews, K., Ntem, A. \& Leatwick, S. (2018). What We Talk About When We Talk About Students as Partners. International Journal for Students as Partners, 2(2), 1-9. https://doi.org/10.15173/ijsap.v2i2.3790

Dekker, H. \& Wolf, S. (2016). Re-inventing research-based teaching and learning. Meeting of European University Association. Brussels.

Durning, B. \& Jenkins, A. (2005). Teaching/research relations in departments: The perspectives of built environment academics. Studies in Higher Education, 30, 407-426. https://doi.org/10.1080/03075070500160046

Elken, M. \& Wollscheid, S. (2016). The relationship between research and education: typologies and indicators. Oslo: Nordic Institute for Studies in Innovation, Research and Education.

Fung, D. (2017). A connected curriculum for higher education. London: UCL Press.

Gibbons, M., Limoges, C., Nowotny, H., Schwartzman, S., Scott, P. \& Trow, M. (1994). The new production of knowledge: the dynamics of science and research in contemporary societies. Sage.

Griffioen, D., Groen, A. \& Nak, J. (2019). The integration of research in the higher education curriculum: A systematic review. The Higher Education Journal of Learning and Teaching, 10(1), https://doi.org/10.24384/vhs6-1j85

Harland, T. (2016). Teaching to enhance research. Higher Education Research and Development. http://dx.doi.org/10.1080/07294360.2015.1107876

Hattie, J. \& Marsh, H. (1996). The relationship between research and teaching: A meta-analysis. Review of Educational Research, 66(4), 507-542. https://doi.org/10.3102/00346543066004507

Hattie, J. \& Marsh, H. (2004). One journey to unravel the relationship between research and teaching. Research and Teaching: Closing the Divide? An International Colloquium. Winchester.

Healey, M. (2005). Linking research and teaching exploring disciplinary spaces and the role of inquiry-based learning. A R. Barnett, Reshaping the university: new relationships between research, scholarship and teaching (p. 67-78). Maidenhead: McGraw/Hill / Open University Press.

Healey, M. \& Healey, R. (2018). 'It depends': Exploring the context-dependent nature of 'Students as Partners' practices and policies. International Journal for Students as Partners, 2(1), 1-10. https://doi.org/10.15173/ijsap.v2i1.3472

Healey, M. \& Jenkins, A. (2009). Developing Undergraduate Research and Enquiry. York: The Higher Education Academy.

Healey, M. \& Jenkins, A. (2018). The role of academic developers in embedding high-impact undergraduate research and inquiry in mainstream higher education: twenty years' reflection. International Journal for Academic Development, 23(1), 52-64. https://doi.org/10.1080/1360144X.2017.1412974

Healey, M., Flint, A. \& Harrington, K. (2014). Engagement through partnership: students as partners in learning and teaching in higher education. York: The Higher Education Academy.

Hensley, M. (2015). A survey of instructional support for undergraduate research programs. Portal: Libraries and the Academy, 15(4), 719-762.

Hodson, D. (1992). An exploration of some issues relating to integration in science and science education. International Journal of Science Education, 14(5), 541-562.

Huff, S. \& Huff, J. (2011). Re-focusing the business school agenda. British Journal of Management, 12(s1), s49-s54. https://doi.org/10.1111/1467-8551.12.s1.6

Jenkins, A. \& Healey, M. (2005). Institutional strategies to link teaching and research. London: The Higher Education Academy.

Keselman, A. (2003). Supporting inquiry learning by promoting normative understanding of multivariable causality. Journal of Research in Science Teaching, 40, 898-921. https://doi.org/10.1002/tea.10115 
Knight, S., Van Wyk, J. \& Mahomed, S. (2016). Teaching research: a programme to develop research capacity in undergraduate medical students at the University of KwaZulu-Natal, South Africa. BMC Medical Education, 16(61), 1-8. https://doi.org/10.1186/s12909-016-0567-7

Laidlaw, A., Aiton, J., Struthers, J. \& Guild, S. (2012). Developing research skills in medical students: AMEE Guide No. 69. Medical Teacher, 34(9), 754-771. https://doi.org/10.3109/0142159X.2012.704438.

LERU. (2017). Excellent education in research-rich universities. Leuven: League of European Research Universities.

Levy, P. \& Petrulis, R. (2012). How do first-year university students experience inquiry and research, and what are the implications for the practice of inquiry-based learning? Studies in Higher Education, 37(1), 85-101. https://doi.org/10.1080/03075079.2010.499166

McKenzie, A., Griggs, L., Snell, R. \& Meyers, D. (2018). The myth of the teaching-research nexus. Legal Education Review, 28(1), 1-20.

Russell Group. (2014). A passion for learning: The student experience at Russell Group universities. The Russell Group of Universities.

Saunders, M. (2011). The management researcher as practitioner. A C. Cassell \& W. Lee, Challenges and controversies in management (p. 243-256). London: Taylor and Francis.

Trowler, P. \& Wareham, T. (2008). Tribes, territories, research and teaching: Enhancing the teaching-research nexus. York: The Higher Education Academy.

Visser-Wijnveen, G., Van Driel, J., Van der Rijst, R., Verloop, N. \& Visser, A. (2010). The ideal research-teaching nexus in the eyes of academics: Building profiles. Higher Education Research \& Development, 29(2), 195-210. https://doi.org/10.1080/07294360903532016 